\title{
Monitoring the effects of tourism on whale shark Rhincodon typus behaviour in Mozambique
}

\author{
Peter J. Haskell, Andrem McGowan, Anna Westing, Adriana Méndez- \\ Jiménez, Christoph A. Rohner, Kym Collins, Marcela Rosero-Caicedo \\ Jodi Salmond, Ara Monadjem, Andrea D. Marshall and Simon J. Pierce
}

\begin{abstract}
The whale shark Rhincodon typus is a popular focal species in the marine tourism industry. We analysed 689 encounters with at least 142 individual sharks during 2008-2010 to assess their behaviour in the presence of swimmers at Tofo Beach, Mozambique. Sharks varied in size (estimated $3.0-9.5 \mathrm{~m}$ total length) and the majority (74\%) were males. The sharks displayed avoidance behaviours during $64.7 \%$ of encounters. Encounter duration decreased significantly, from 12 minutes $37 \mathrm{~s}$ with undisturbed sharks to 8 minutes $25 \mathrm{~s}$ when sharks expressed avoidance behaviours, indicating that interactions with tourists affected the sharks' short-term behaviour. However, during the 2.5-year study period we found no trend in the mean encounter duration, the overall expression of avoidance behaviour or the likelihood of an individual shark exhibiting avoidance behaviours. Potential effects of tourism may be mitigated by the non-breeding status and transient behaviour of sharks at this aggregation site.
\end{abstract}

Keywords Behavioural observations, ecotourism, Mozambique, Rhincodon typus, risk assessment, tourism management, whale shark

This paper contains supplementary material that can be found online at http://journals.cambridge.org

Peter J. Haskell* and Andrew McGowan School of Biosciences, University of Exeter, Penryn, UK

Anna Westling, Adriana Méndez-Jiménez, Kym Collins, Marcela RoseroCaicedo and Jodi Salmond All Out Africa Research Unit, Lobamba, Swaziland

Christoph A. Rohner $\dagger$, Andrea D. Marshall $\neq$ and Simon J. Pierce $\$$ (Corresponding author) Marine Megafauna Foundation, Tofo Beach, Inhambane, Mozambique. E-mail simon@marinemegafauna.org

Ara Monadjem All Out Africa Research Unit, Department of Biological Sciences, University of Swaziland, Kwaluseni, Swaziland

*Also at: Marine Megafauna Foundation, Tofo Beach, Inhambane, Mozambique $\dagger$ Also at: School of Geography, Planning and Environmental Management, The University of Queensland, St Lucia, Australia, and Climate Adaptation Flagship, CSIRO Marine and Atmospheric Research, EcoScience Precinct, Dutton Park, Australia

¥Also at: Wild Me, Tofo Beach, Inhambane, Mozambique

$\S$ Also at: All Out Africa Research Unit, Lobamba, Swaziland

Received 1 February 2013. Revision requested 29 April 2013.

Accepted 5 September 2013. First published online 10 October 2014.

\section{Introduction}

T iewing sharks in their natural setting is a popular tourism activity (Gallagher \& Hammerschlag, 2011) and the income accrued creates an incentive to manage these charismatic species as a non-consumptive resource (Brunnschweiler, 2010; Clua et al., 2011; Vianna et al., 2012). However, studies on elasmobranchs have documented situations in which marine tourism has negative effects, including behavioural changes and increased energetic costs (Pierce et al., 2010; Fitzpatrick et al., 2011). Improved understanding of the actual or potential effects of tourism interactions is important for mitigating or avoiding longer-term effects and ultimately safeguarding employment and the tourism infrastructure.

The whale shark Rhincodon typus is the largest fish and an iconic species for tourism (Gallagher \& Hammerschlag, 2011). Commercial whale shark interaction tours began in 1993 in Western Australia after a seasonal aggregation of the species was discovered within the Ningaloo Marine Park (Davis et al., 1997). In 2006 the whale shark tourism industry at this site was valued at AUD 6 million annually (Catlin et al., 2010). Whale shark tourism industries have now developed at several locations in all three tropical oceans and are mostly based on the presence of predictable seasonal feeding aggregations of sharks exploiting ephemeral bursts in local productivity, such as mass fish or coral spawning events (Taylor, 1996; de la Parra Venegas et al., 2011). The global revenue from whale shark tourism was provisionally estimated to be USD 42 million in 2007 (Graham, 2007).

Whale sharks are categorized as Vulnerable on the IUCN Red List (Norman, 2005). Although the economic value or potential of whale shark tourism has helped to justify legal protection for the species in some countries, concerns have also been raised that specialist tourism industries could negatively affect the sharks. Sightings of whale sharks at Gladden Spit in Belize declined during 1998-2003 (Graham \& Roberts, 2007) and, based on anecdotal reports from guides, remained low at least until 2007 (Graham, 2007). Graham (2007) suggested that the rapid increase in diver numbers at this site may have led to disturbance of snapper spawning behaviour (the main driver of whale shark presence), and the whale sharks themselves, although a dedicated study on disturbance by divers did not identify a 
direct effect on the sharks (Heyman et al., 2010). Propeller injuries from small boats have also been observed on whale sharks at several aggregation sites (Rowat et al., 2007; Speed et al., 2008). Studies of the short-term behavioural responses of sharks to tourists and boats at Ningaloo Reef (Norman, 1999), Donsol in the Philippines (Quiros, 2007) and Tofo Beach in Mozambique (Pierce et al., 2010) have revealed that sharks routinely display avoidance behaviours, including banking, eye-rolling, fast swimming and diving, in response to close approaches by swimmers or boats.

The ecological, social and economic sustainability of whale shark tourism at Ningaloo Reef was reviewed by Mau (2008). Although long-term empirical data on whale shark behaviour in the area were not available, the industry was judged to be ecologically sustainable. This was based on the lack of observed interruption of feeding behaviour, which may take place largely at night or at least outside tourist interaction times (Taylor, 2007), the regular re-sightings of philopatric sharks (Holmberg et al., 2008, 2009), and the lack of reproductive behaviour observed in this juvenile male-biased population (Meekan et al., 2006; Norman \& Stevens, 2007). However, concerns were raised about the potential for injury from boat strikes (Speed et al., 2008) and an apparent decline in mean size over time (Bradshaw et al., 2008). Aside from Ningaloo Reef, where the sharks have been relatively well studied, the longer-term sustainability of whale shark tourism has not been considered explicitly.

Here we examine the tourism industry at Tofo Beach (Praia do Tofo) in Mozambique, an international hotspot for whale shark encounters (Pierce et al., 2010). Whale shark interactions are a key attraction for international divers visiting the country but a lack of official management has raised questions about the sustainability of the industry (Pierce et al., 2010; Tibiriçá et al., 2011), particularly after a significant decline in sightings during 2005-2011 (Rohner et al., 2013). Previous work at Tofo Beach has examined how interactions can be managed to minimize the potential for short-term negative effects on the sharks (Pierce et al., 2010). Here we extend that dataset to evaluate whether longitudinal encounter data reveal evidence of an increasing frequency of avoidance behaviours overall and whether individual-based analyses show evidence of changing avoidance behaviours over time. We consider the implications of these data and evaluate the longer-term implications for the ecology of whale sharks at this site.

\section{Methods}

The village of Tofo Beach is situated in the Inhambane province of Mozambique, c. $400 \mathrm{~km}$ north-east of the capital city, Maputo (Fig. 1). A full site overview and description of the commercial whale shark tourism industry in Tofo

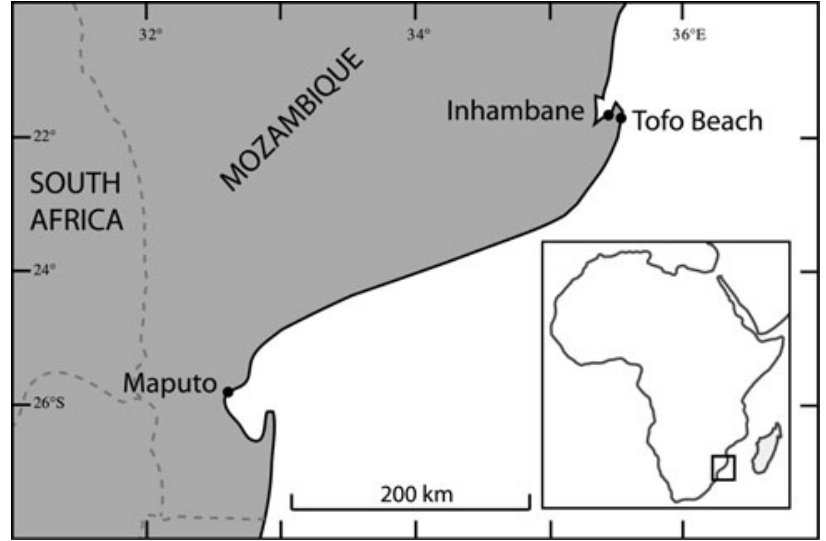

FIg. 1 Tofo Beach, Mozambique. The rectangle on the inset shows the location of the main map in south-east Africa.

are provided by Pierce et al. (2010). Tourism operators offer daily 2-hour snorkelling trips that aim to locate whale sharks and other marine megafauna. Vessels typically survey a $6 \mathrm{~km}$ stretch of coastline south of Tofo, between the surf line and c. 1,000 $\mathrm{m}$ from the shore, in waters c. 5-30 m deep. Sharks are located through visual inspection of the water surface, where it is often possible to spot their dark silhouettes or exposed fins. The boat is then positioned in relation to the shark's direction of travel and clients enter the water to interact with the shark.

We collected data during January 2008-June 2010, except during July and August 2008 when no sampling trips took place. Upon locating a whale shark, observers entered the water alongside clients and recorded the total number of swimmers and environmental characteristics, including weather conditions (categorized as sunny, slightly overcast, overcast or raining), Beaufort sea state and underwater visibility. The total length of the shark was estimated visually (Rohner et al., 2011) and the sex identified by the presence or absence of claspers on the pelvic fins. The presence and location of any injuries or scars were noted and categorized post hoc as either major or minor (Speed et al., 2008). A basic ethogram of each shark's behaviour in the presence of swimmers was produced to record slow swimming, equating to normal behaviour; fast swimming, where there was an obvious increase in the shark's tail-beat frequency; diving, where the shark dived away from the surface; banking, where the shark rolled its back towards swimmers; changing direction, where the shark altered its direction of swimming in the presence of swimmers; and any other obvious avoidance behaviours, such as the violent shudder reported by Quiros (2007). Observations of feeding behaviour were also noted when they occurred. The total encounter duration, defined as the time between the first swimmer entering the water and the last swimmer returning to the boat, was recorded (in minutes) following each interaction. When possible, standardized identification 
photographs of both the left and right flanks of each shark were taken and uploaded to the global Wildbook for Whale Sharks photo-identification library (Arzoumanian et al., 2005; Marshall \& Pierce, 2012). Each of these encounters was then assigned to a new or previously identified shark in the library.

It was difficult to establish whether behaviours exhibited by whale sharks in the presence of swimmers would also occur in a natural, undisturbed setting. Within-effect comparisons (i.e. behaviour in the presence of swimmers) were therefore employed instead of attempting to determine cause-and-effect relationships. This approach is useful in cases where there are no baseline or control data, and focuses on assessing behavioural responses under gradations of the effect (Bejder \& Samuels, 2003). Fast swimming, diving, banking and changing direction are typically classified as avoidance behaviours in whale sharks (Norman, 1999; Quiros, 2007; Pierce et al., 2010). When these or other obvious avoidance behaviours were observed during an interaction they were each assigned a score of one. The total score at the end of each encounter was thus equal to the total number of avoidance behaviours observed. All statistical analyses were carried out using $R$ v. 2.11.o (R Development Core Team, 2012), with MASS and nlme.

The relationship between avoidance score and encounter duration was tested using a generalized linear mixed model approach. Encounter duration, log transformed to ensure that error structure was normally distributed, was used as the response variable. Avoidance score was used as the explanatory variable and shark identification was added as a random effect to avoid pseudo replication. Given the significant relationship between avoidance score and encounter duration (see results; Pierce et al., 2010), encounter duration was used in all further analyses as a proxy for avoidance. A further model was fitted to determine which variables significantly affected encounter duration. Encounter duration was entered as the response variable and tested against nine main effect explanatory variables: whale shark variables (size, sex, presence/absence of scarring or feeding behaviour), environmental variables (weather, sea state (o-4) and underwater visibility), number of swimmers present during an encounter, and the Julian day (Day $1=9$ January 2008). We tested second-order interactions between all combinations of whale shark variables; all combinations of environmental variables; size, sex and scarring and all environmental variables; and between the number of swimmers and underwater visibility. Year and month of encounter were entered as nested random effects. Only encounters in which shark identity had been confirmed were used in the analysis; a single interaction was randomly selected from those individuals for which multiple encounters had been recorded. We used a generalized linear model to test for a significant relationship between the amount of scarring on an individual and its total length.

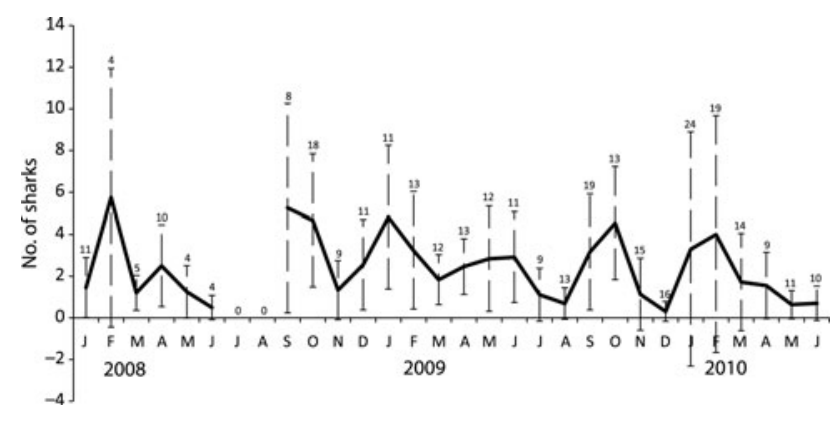

FIG. 2 Mean $( \pm \mathrm{SD})$ number of whale sharks Rhincodon typus sighted per daily trip during the 30-month sampling period. Numbers above the bars denote the number of sampling days in that month.

A generalized linear model was fitted, using the number of encounters as the response variable and search effort (in hours) and year as explanatory variables, to establish whether encounter rate changed over the course of the study. As the dataset ended in June 2010, a second model was fitted to 6-month periods, using the number of encounters as the response variable and search effort and 6-month block as explanatory variables. A quasi-poisson error structure was used for both analyses because of overdispersion of residual deviance. A third model was used to test for a change in encounter duration during the study period, using log-transformed encounter duration as the response variable and month and year as explanatory variables. We used $\chi^{2}$ to test for a population-level increase in avoidance response over the five 6-month periods. A generalized linear mixed effects model was used to test whether the likelihood of avoidance was related to the number of previous encounters in which the whale shark had been successfully identified and its behaviours recorded over the study period. We used the Wildbook library to establish how many previous encounters had been recorded for each individual shark. A binomial score for avoidance was used as the response variable, encounter number as the explanatory variable, and shark identity as a random factor. Significance was accepted at the $95 \%$ confidence interval in all analyses.

\section{Results}

We recorded a total of 689 whale shark encounters from 328 trips during January 2008-June 2010, with a total search effort of 476.5 hours. The mean encounter rate was $2.73 \pm \mathrm{SD}$ 0.17 per trip, with $0-14$ encounters recorded on each trip, equating to $1.46 \pm \mathrm{SD} 0.10$ sharks per hour of search effort. At least one shark was sighted on $77.1 \%$ of trips. There was no significant trend in sightings over the course of the study (linear regression, $\mathrm{df}=27, \mathrm{P}=0.260$; Fig. 2). A total of 142 sharks were positively identified using the Wildbook photo-identification library. Of 128 sexed sharks, 33 were female $(25.8 \%)$ and 95 were male $(74.2 \%)$, which was 


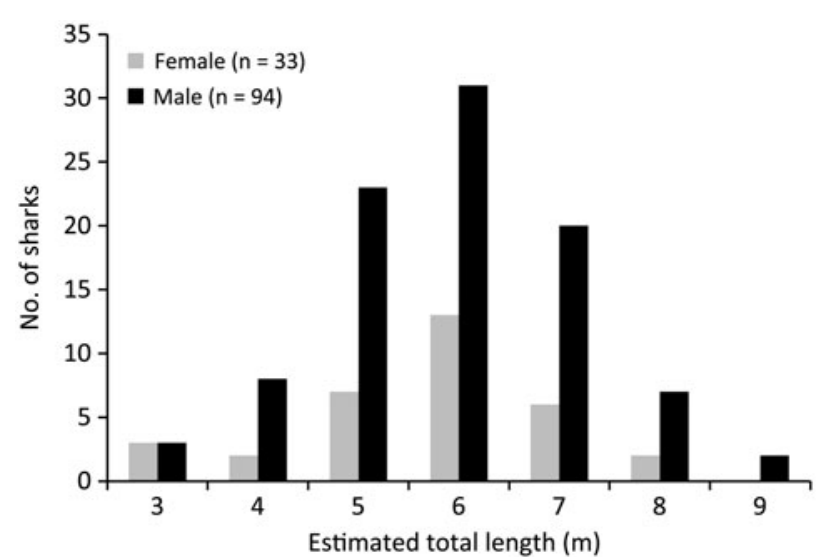

FIG. 3 Frequency distribution of the estimated lengths of photo-identified sharks.

significantly different from a $1: 1$ sex ratio $\left(\chi_{1}^{2}=30.031\right.$, $\mathrm{P} \leq$ 0.001). The mean total length was $5.85 \pm$ SD $1.28 \mathrm{~m}$ (range $3-8.5 \mathrm{~m}$ ) for females and $6.14 \pm \mathrm{SD} 1.24 \mathrm{~m}$ (range 3-9.5 m) for males (Fig. 3), with no significant difference between the sexes ( $t$-test, $t=-1.144, \mathrm{df}=125, \mathrm{P}=0.255$ ). The total number of encounters with identified sharks (counted as the number of days on which interactions with a particular shark were recorded) was 1-5 over the course of the study, although the inclusion of additional data from the Wildbook library showed that $42 \%$ of the individual sharks considered in this study had been exposed to swimmers prior to the start of this work in 2008. Overall, sharks were encountered on a mean of $3.08 \pm$ SD 2.13 occasions, with up to 12 encounters per individual (Fig. 4). The reliance on suitable photographs having been submitted to the library means that these figures represent the minimum number of previous encounters. Scarring was observed on $53.3 \%$ of identified individuals and whale sharks were observed feeding during $19.5 \%$ of all encounters.

The mean duration of encounter was 9 minutes $46 \mathrm{~s} \pm$ SD 8 minutes $18 \mathrm{~s}(\mathrm{n}=613)$. One or more avoidance responses were recorded during $67.5 \%$ of encounters. Evaluation of 184 encounters with 132 identified sharks indicated that encounter duration was significantly related to expressed avoidance response (generalized linear mixed model, $\left.\chi_{3}^{2}=15.046, P=0.002\right)$. The mean duration of encounter when a shark showed no avoidance was $12 \mathrm{~min}$ utes $37 \mathrm{~s} \pm$ SD 8 minutes $58 \mathrm{~s}(\mathrm{n}=190)$, which is significantly longer than encounters with sharks that exhibited avoidance (generalized linear mixed model, $\chi_{1}^{2}=14.255$, $\mathrm{P}<0.001)$. There was no significant difference in the duration of encounters where one or more avoidance behaviours were expressed (generalized linear mixed model, $\left.\chi_{2}^{2}=0.791, \mathrm{P}=0.673\right)$; mean duration of such encounters was 8 minutes $25 \mathrm{~s} \pm \mathrm{SD} 7$ minutes $21 \mathrm{~s}(\mathrm{n}=397)$. A binomial response (avoidance or no avoidance) was therefore used in subsequent analyses.

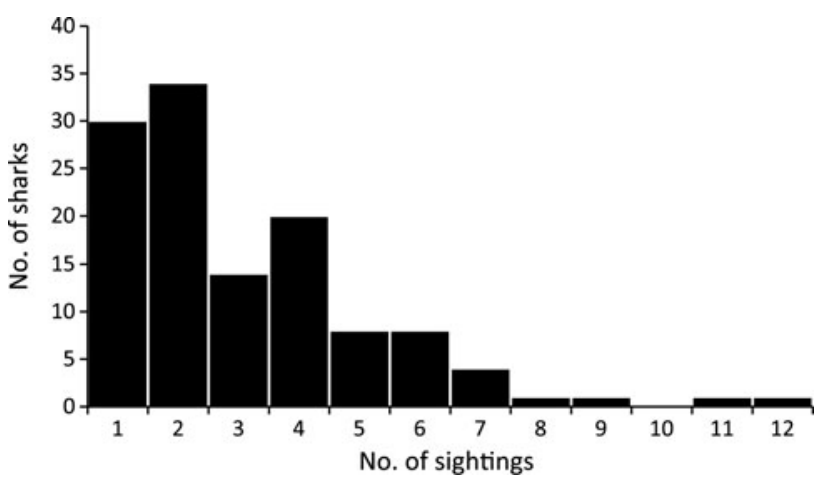

FIG. 4 The total number of sightings (unique encounter days) for each photo-identified shark.

All potential explanatory variables were present in 170 encounters and, after controlling for multiple encounters with individual sharks, 120 encounters were available to test for other significant variables affecting encounter duration. A linear mixed effects model, with year and month retained as nested random effects, demonstrated that scarring was highly significant (linear mixed effects, $\chi_{2}^{2}=10.953$, $\mathrm{P}=0.004)$. Encounters with individuals that had no apparent scarring were significantly shorter than with individuals that had some degree of scarring (linear mixed effects, $\left.\chi_{1}^{2}=7.927, \mathrm{P}=0.005\right)$; the severity of the scarring did not significantly affect encounter duration (linear mixed effects, $\left.\chi_{1}^{2}=3.027, \mathrm{P}=0.082\right)$. There was no significant relationship between the total length of an individual and the degree of scarring observed (ANOVA, $F_{(2,627)}=2.390, \mathrm{P}=0.122$ ). Encounters were significantly longer when sharks were feeding (linear mixed effects, $\chi_{1}^{2}=5.608, P=0.018$ ) and when more swimmers were present (linear mixed effects, $\chi_{1}^{2}=5.580, \mathrm{P}=0.018$ ).

The number of whale sharks encountered was not correlated with search effort between years (ANOVA, $\left.F_{(1,249)}=1.134, \mathrm{P}=0.288\right)$. There was a significant difference in encounter rates between years (ANOVA, $F_{(2,249)}=5.446$, $\mathrm{P}=0.005$ ) but analysis of 6-month blocks indicates that the source of this difference was the second half of 2008 , for which July and August were not included (ANOVA, $\left.F_{(4,247)}=8.591, \mathrm{P} \leq 0.001\right)$. Encounter rate was generally low during the austral winter, so excluding these 2 months may have affected this result. No other variables were significant. There was no significant difference in the frequency of avoidance behaviours expressed between the five 6-month periods $\left(\chi_{4}^{2}=4.34, \mathrm{P}=0.362\right)$. Encounter duration was significantly shorter in 2008 (8 minutes $2 \mathrm{~s} \pm$ SD 8 minutes $32 \mathrm{~s}$ ) than in 2009 (10 minutes $38 \mathrm{~s} \pm \mathrm{SD} 8$ minutes $7 \mathrm{~s}$ ) and 2010 (10 minutes $37 \mathrm{~s} \pm \mathrm{SD} 7$ minutes $56 \mathrm{~s}$; ANOVA, $\left.F_{(2,610)}=17.925, \mathrm{P} \leq 0.001\right)$. A total of 204 encounters with 142 whale sharks were analysed to establish that the number of previous encounters with swimmers did not affect the likelihood that a whale shark would display 
avoidance behaviour (generalized linear mixed model, $\left.\chi_{1}^{2}=1.693, \mathrm{P}=0.193\right)$.

\section{Discussion}

We found no significant longitudinal effects on encounter duration or the raw proportion of avoidance behaviours expressed over the 30-month study period. Furthermore, there was no significant relationship between the number of previous tourist encounters and the likelihood of avoidance behaviours being displayed by individual sharks. At this stage there is no evidence of short-term avoidance behaviours translating into medium- to longer-term behavioural change among the sharks present in Mozambican waters.

The potential negative effects of tourism may be ameliorated by the ecology and population structure of whale sharks in Mozambique. The majority of sharks encountered were male $(74 \%)$. Maturity in male sharks occurs when they reach a total length of c. $8 \mathrm{~m}$, based on records from Ningaloo Reef (Norman \& Stevens, 2007), and in female sharks at a total length of $>8.7 \mathrm{~m}$, based on South African and other records (Beckley et al., 1997; Norman \& Stevens, 2007). Given that no sharks of total length $>9.5 \mathrm{~m}$ or $<3 \mathrm{~m}$ were encountered, most sharks were immature and were probably several years old at the time of first sighting (Wintner, 200o). Therefore, tourism at this site is unlikely to interfere with reproduction, if it does in fact occur in these waters. The majority $(52 \%)$ of sharks had only one or two encounters recorded on the Wildbook photo-identification library by 30 June 2010 (with the earliest record from 2003), including from this study, suggesting that many of the sharks are transient to the area, as noted in other aggregations (Holmberg et al., 2008; Rowat et al., 2009; Fox et al., 2013). There was no evidence of a learnt avoidance behaviour amongst individual sharks and, based on data from the Philippines (Quiros, 2007), a degree of habituation may be more likely to occur.

The percentage of whale sharks observed feeding during daylight hours at Tofo $(19.5 \%)$ is comparable to the rates reported at Donsol in the Philippines (13\% in 2004 and $36 \%$ in 2005; Quiros, 2007) but substantially lower than the 69\% reported from Bahía de Los Angeles, Mexico, where researchers targeted feeding whale sharks (Nelson \& Eckert, 2007). Contrary to results from the Philippines, where feeding sharks were 1.84 times more likely to exhibit a dive response in the presence of swimmers (Quiros, 2007), encounter durations in this study were significantly longer when feeding behaviour was observed. Whale sharks are flexible in their foraging strategies, depending on prey type and vertical distribution (Graham et al., 2006; Nelson \& Eckert, 2007; Taylor, 2007; Brunnschweiler et al., 2009; Motta et al., 2010), so the effects of tourism on feeding are likely to be context-specific.
Whale shark encounters were spatially aggregated along $9 \mathrm{~km}$ of coast immediately south of Tofo Beach. Although the sharks are also sighted more widely along the Mozambican coast (Cliff et al., 2007), the small size of the primary aggregation area and its almost complete daily search coverage by commercial operators suggest the possibility of displacement if whale sharks have negative interactions with swimmers or boats. Over half $(53 \%)$ of identified sharks had some form of scarring, although not all of these were from anthropogenic sources such as propeller strikes. This percentage is lower than that recorded in Djibouti, where propeller or boat strike scars were observed on $65 \%$ of identified sharks (Rowat et al., 2007), but emphasizes the importance of working with skippers to ensure that a safe minimum distance from the sharks is maintained (Pierce et al., 2010). Although tourism operators have not perceived a shift in whale shark distribution, the lack of standardized spatial sampling coverage precludes a definitive assessment.

Our results support the use of encounter duration as a means of measuring the effect of swimmer presence on whale shark behaviour, as sharks that are disturbed will routinely end an encounter by diving or increasing their swimming speed. However, it is important to note that encounter duration, although a useful proxy of avoidance, may only be able to provide resolution at the binomial scale (avoidance or no avoidance). Encounter duration has previously been used to quantify avoidance by Hector's dolphins Cephalorhynchus hectori of swimmers in New Zealand (Bejder et al., 1999) and to assess long-term trends in encounters with dwarf minke whales Balaenoptera acutorostrata on the Great Barrier Reef, Australia (Birtles et al., 2002). However, these studies used different definitions of encounter duration: Bejder et al. (1999) defined it as the length of time that a swimmer spent within $200 \mathrm{~m}$ of the nearest dolphin and Birtles et al. (2002) defined it as the time between the first sighting of a whale and the end of the vessel's contact with that whale. Here we define encounter duration as the time between the first swimmer entering the water in the presence of a whale shark and the last swimmer returning to the boat. This definition could be less useful in areas with significant currents or where the boat would take longer to retrieve swimmers.

We found a positive relationship between the number of swimmers and encounter duration. This result may be an artefact of the definition in use, as larger groups of swimmers are likely to contain members with a wider range of swimming abilities. The presence of more able swimmers is likely to lead to an increase in encounter duration, as they are able to maintain visual contact with a shark for longer than slower or less fit individuals. Another important point to consider in future work is the number of swimmers that are actually in contact with the shark from a behavioural perspective, investigating how swimmer proximity 
may influence these results. Future studies that rely on inwater observers could trial re-defining encounter duration as the time between the observer's first and last visual contact of the shark underwater, to reduce the influence of swimming ability and group size on results.

Consistent with results from Quiros (2007) but contrary to Norman (1999) encounter duration was significantly longer with scarred whale sharks. This could be because scarred individuals have slower reaction times and a reduced level of agility as a consequence of their previous injuries. However, the severity of scarring did not significantly alter encounter duration. Another hypothesis is that older individuals, who would presumably be more likely to have accumulated scars, show less avoidance than younger individuals. However, we found no significant relationship between shark size and the severity of scarring. A third plausible explanation is that some sharks have a slower natural reaction time to potential threats and are therefore more likely to accumulate injuries than sharks with faster reactions. Sharks may also vary in their inquisitiveness. Further research is required to confirm or refute these hypotheses.

A mean of 11.4 swimmers per encounter was recorded. This exceeds the maximum recommended by most management plans, which limit swimmer numbers to three in Mexico (Remolina Suárez et al., 2007) and 10 in Australia (Catlin \& Jones, 2010), although these limits may be partially influenced by operational constraints in those locations. From a management perspective it is also important to consider customer satisfaction with the experience, which can be significantly reduced in crowded scenarios (Davis et al., 1997).

The inclusion of well-defined and easily observed parameters of known significance that can be recorded by either trained specialists (e.g. researchers) or non-specialist observers (e.g. tour operators or volunteers) would increase the amount of information available, enabling routine sustainability assessments and facilitating inter-site comparisons (Graham, 2007). We have created a template data collection sheet (Supplementary Material 1), which is currently in use in Mozambique. We also encourage the submission of standardized photographs of all whale sharks encountered to the global whale shark photo-identification library (Wild Me, 2003). This facilitates the incorporation of individual-based analyses into future studies, concurrently enabling more accurate regional and ocean-wide studies of population size and interconnectivity (Graham, 2007; Brooks et al., 2010).

With increasing global interest in human interactions with whale sharks there is a clear need for the implementation of monitoring initiatives at tourism sites to understand and avoid long-term anthropogenic effects. Other important whale shark tourism sites, such as those in Mexico, the Seychelles and Western Australia, have similar characteristics in terms of population structure. The results of this study demonstrate that encounter duration is a useful metric for assessing whale shark behaviour, and provide a template for future studies in Mozambique and other locations.

\section{Acknowledgements}

We thank the All Out Africa volunteers and staff for their efforts in collecting the majority of the data used in this study, and Marine Megafauna Foundation staff, volunteers and students who also contributed. We thank the developers of, and contributors to, the Wildbook whale shark database. The support of Casa Barry Lodge and Tofo Scuba throughout the field portion of the project is greatly appreciated. This study was made possible by support from the National Marine Aquarium (UK), Shark Foundation, GLC Charitable Trust, Project AWARE Foundation, the Rufford Small Grant Foundation, PADI Foundation, Ocean Revolution, Fondation Ensemble and private donors. We thank Philip Dearden, Adrian Gutteridge, Conrad Speed and the anonymous reviewers for their comments on this article.

\section{References}

Arzoumanian, Z., Holmberg, J. \& Norman, B. (2005) An astronomical pattern-matching algorithm for computer-aided identification of whale sharks Rhincodon typus. Journal of Applied Ecology, 42, 999-1011.

Beckley, L.E., Cliff, G., Smale, M.J. \& Compagno, L.J.V. (1997) Recent strandings and sightings of whale sharks in South Africa. Environmental Biology of Fishes, 50, 343-348.

Bejder, L., Dawson, S.M. \& Harraway, J.A. (1999) Responses by Hector's dolphins to boats and swimmers in Porpoise Bay, New Zealand. Marine Mammal Science, 15, 738-750.

Bejder, L. \& SAMUELS, A. (2003) Evaluating the effects of nature-based tourism on cetaceans. In Marine Mammals: Fisheries, Tourism and Management Issues (eds N. Gales, M. Hindell \& R. Kirkwood), pp. 229-256. CSIRO Publishing, Melbourne, Australia.

Birtles, R.A., Arnold, P.W. \& Dunstan, A. (2002) Commercial swim programs with dwarf minke whales on the northern Great Barrier Reef, Australia: some characteristics of the encounters with management implications. Australian Mammalogy, 24, 23-38.

Bradshaw, C.J.A., Fitzpatrick, B.M., Steinberg, C.C., Brook, B.W. \& MEEKAN, M.G. (2008) Decline in whale shark size and abundance at Ningaloo Reef over the past decade: the world's largest fish is getting smaller. Biological Conservation, 141, 1894-1905.

Brooks, K., Rowat, D., Pierce, S.J., Jounnnet, D. \& Vely, M. (2010) Seeing spots: photo-identification as a regional tool for whale shark identification. Western Indian Ocean Journal of Marine Science, 9, 185-194.

Brunnschweiler, J.M. (2010) The Shark Reef Marine Reserve: a marine tourism project in Fiji involving local communities. Journal of Sustainable Tourism, 18, 29-42.

Brunnschweiler, J.M., Baensch, H., Pierce, S.J. \& Sims, D.W. (2009) Deep-diving behaviour of a whale shark, Rhincodon typus, 
during long-distance movement in the western Indian Ocean. Journal of Fish Biology, 74, 706-714.

Catlin, J. \& Jones, R. (2010) Whale shark tourism at Ningaloo Marine Park: a longitudinal study of wildlife tourism. Tourism Management, 31, 386-394.

Catlin, J., Jones, T., Norman, B. \& Wood, D. (2010) Consolidation in a wildlife tourism industry: the changing impact of whale shark tourism expenditure in the Ningaloo coast region. International Journal of Tourism Research, 12, 134-148.

Cliff, G., Anderson-Reade, M.D., Aitken, A.P., Charter, G.E. \& Peddemors, V.M. (2007) Aerial census of whale sharks (Rhincodon typus) on the northern KwaZulu-Natal coast, South Africa. Fisheries Research, 84, 41-46.

Clua, E., Buray, N., Legendre, P., Mourier, J. \& Planes, S. (2011) Business partner or simple catch? The economic value of the sicklefin lemon shark in French Polynesia. Marine and Freshwater Research, 62, 764-770.

Davis, D., Banks, S., Birtles, A., Valentine, P. \& Cuthill, M. (1997) Whale sharks in Ningaloo Marine Park: managing tourism in an Australian marine protected area. Tourism Management, 18, 259271.

de la Parra Venagas, R., Hueter, R.E., Gonzales Cano, J., Tyminski, J.P., Gregorio Remolina, J., Maslanka, M. et al. (2011) An unprecedented aggregation of whale sharks, Rhincodon typus, in Mexican coastal waters of the Caribbean Sea. PLoS ONE, 6(4), e18994.

Fitzpatrick, R., Abrantes, K.G., Seymour, J. \& Barnett, A. (2011) Variation in depth of whitetip reef sharks: does provisioning ecotourism change their behaviour? Coral Reefs, 30, 569-577.

Fox, S., Foisy, I., de la Parra Venegas, R., Galván Pastoriza, B. E.Graham, R.T., Hoffmayer, E.R. et al. (2013) Population structure and residency of whale sharks Rhincodon typus at Utila, Bay Islands, Honduras. Journal of Fish Biology, 83, 574-587.

Gallagher, A.J. \& Hammerschlag, N. (2011) Global shark currency: the distribution, frequency, and economic value of shark tourism. Current Issues in Tourism, 14, 797-812.

Graham, R.T. (2007) Whale sharks of the western Caribbean: an overview of current research and conservation efforts and future needs for effective management of the species. Gulf and Caribbean Research, 19, 149-159.

Graham, R.T. \& Roberts, C.M. (2007) Assessing the size, growth rate and structure of a seasonal population of whale sharks (Rhincodon typus Smith 1828) using conventional tagging and photo identification. Fisheries Research, 84, 71-80.

Graham, R.T., Roberts, C.M. \& Smart, J.C.R. (2006) Diving behaviour of whale sharks in relation to a predictable food pulse. Journal of the Royal Society Interface, 3, 109-116.

Heyman, W.D., Carr, L.M. \& Lobel, P.S. (2010) Diver ecotourism and disturbance to reef fish spawning aggregations: it is better to be disturbed than to be dead. Marine Ecology Progress Series, 419, 201210.

Holmberg, J., Norman, B. \& Arzoumanian, Z. (2008) Robust, comparable population metrics through collaborative photo-monitoring of whale sharks Rhincodon typus. Ecological Applications, 18, 222-233.

Holmberg, J., Norman, B. \& Arzoumanian, Z. (2009) Estimating population size, structure, and residency time for whale sharks Rhincodon typus through collaborative photo-identification. Endangered Species Research, 7, 39-53.

Marshall, A.D. \& Pierce, S.J. (2012) The use and abuse of photographic identification in sharks and rays. Journal of Fish Biology, 80, 1361-1379.

MAU, R. (2008) Managing for conservation and recreation: the Ningaloo whale shark experience. Journal of Ecotourism, 7, 208-220.
Meekan, M.G., Bradshaw, C.J.A., Press, M., McLean, C., Richards, A., Quasnichka, S. \& Taylor, J.G. (2006) Population size and structure of whale sharks Rhincodon typus at Ningaloo Reef, Western Australia. Marine Ecology Progress Series, 319, 275-285.

Motta, P.J., Maslanka, M., Hueter, R.E., Davis, R.L., De la Parra, R., Mulvany, S.L. et al. (2010) Feeding anatomy, filter-feeding rate, and diet of whale sharks Rhincodon typus during surface ram filter feeding off the Yucatan Peninsula, Mexico. Zoology, 113, 199-212.

Nelson, J.D. \& Eckert, S.A. (2007) Foraging ecology of whale sharks (Rhincodon typus) within Bahía de Los Angeles, Baja California Norte, Mexico. Fisheries Research, 84, 47-64.

Norman, B. (2005) Rhincodon typus. In The IUCN Red List of Threatened Species v. 2011.2. Http://www.iucnredlist.org [accessed 27 March 2012].

Norman, B.M. (1999) Aspects of the biology and ecotourism industry of the whale shark Rhincodon typus in north-western Australia. MPhil thesis. Murdoch University, Perth, Australia.

Norman, B.M. \& Stevens, J.D. (2007) Size and maturity status of the whale shark (Rhincodon typus) at Ningaloo Reef in Western Australia. Fisheries Research, 84, 81-86.

Pierce, S.J., Mendez-Jimenez, A., Collins, K., Rosero-Caicedo, M. \& Monadjem, A. (2010) Developing a Code of Conduct for whale shark interactions in Mozambique. Aquatic Conservation: Marine and Freshwater Ecosystems, 20, 782-788.

Quiros, A.L. (2007) Tourist compliance to a Code of Conduct and the resulting effects on whale shark (Rhincodon typus) behavior in Donsol, Philippines. Fisheries Research, 84, 102-108.

R Development Core Team (2012) R: A Language and Environment for Statistical Computing. R Foundation for Statistical Computing, Vienna, Austria.

Remolina Suárez, J.F., Pérez Ramírez, J.J., González Cano, J.M., de la Parra Venagas, R., Betancourt Sabatini, N., Trigo MendozA, M. et al. (2007) Whale shark management strategies, with the participation of local stakeholders, in Yum Balam, Mexico. In The First International Whale Shark Conference: Promoting International Collaboration in Whale Shark Conservation, Science and Management (eds T.R. Irvine \& J.K. Keesing), pp. 31-35. CSIRO Marine and Atmospheric Research, Perth, Australia.

Rohner, C.A., Pierce, S.J., Marshall, A.D., Weeks, S.J., Bennett, M.B. \& Richardson, A.J. (2013) Trends in sightings and environmental influences on a coastal aggregation of manta rays and whale sharks. Marine Ecology Progress Series, 482, 153-168.

Rohner, C.A., Richardson, A.J., Marshall, A.D., Weeks, S.J. \& PierCe, S.J. (2011) How large is the world's largest fish? Measuring whale sharks Rhincodon typus with laser photogrammetry. Journal of Fish Biology, 78, 378-385.

Rowat, D., Meekan, M.G., Engelhardt, U., Pardigon, B. \& Vely, M. (2007) Aggregations of juvenile whale sharks (Rhincodon typus) in the Gulf of Tadjoura, Djibouti. Environmental Biology of Fishes, 80, 465-472. Rowat, D., Speed, C.W., Meekan, M.G., Gore, M.A. \& Bradshaw, C.J.A. (2009) Population abundance and apparent survival of the Vulnerable whale shark Rhincodon typus in the Seychelles aggregation. Oryx, 43, 591-598.

Speed, C.W., Meekan, M.G., Rowat, D., Pierce, S.J., Marshall, A.D. \& BRADShaw, C.J.A. (2008) Scarring patterns and relative mortality rates of Indian Ocean whale sharks. Journal of Fish Biology, 72, 1488-1503.

TAYLOR, J.G. (1996) Seasonal occurrence, distribution and movements of the whale shark, Rhincodon typus, at Ningaloo Reef, Western Australia. Marine and Freshwater Research, 47, 637-642.

TAYLOR, J.G. (2007) Ram filter-feeding and nocturnal feeding of whale sharks (Rhincodon typus) at Ningaloo Reef, Western Australia. Fisheries Research, 84, 65-70. 
Tibiriçá, Y., Birtles, A., Valentine, P. \& Miller, D.K. (2011) Diving tourism in Mozambique: an opportunity at risk? Tourism in Marine Environments, 7, 141-151.

Vianna, G.M.S., Meekan, M.G., Pannell, D.J., Marsh, S.P. \& Meeuwig, J.J. (2012) Socio-economic value and community benefits from shark-diving tourism in Palau: a sustainable use of reef shark populations. Biological Conservation, 145, 267-277.

WILD ME (2003) Wildbook for Whale Sharks. Http://www.whaleshark. org [accessed 31 March 2014].

Wintner, S.P. (2000) Preliminary study of vertebral growth rings in the whale shark, Rhincodon typus, from the east coast of South Africa. Environmental Biology of Fishes, 59, 441-451.

\section{Biographical sketches}

Peter Haskell specializes in behavioural ecology and is interested in the role that tourism can play in elasmobranch conservation.
ANDREW McGowan's research interests include avian cooperative breeding, conservation of sea turtles, and tropical seabird populations. Anna Westling is a coral reef ecologist interested in citizen science. Adriana MéndeZ-JiméneZ is interested in the human dimension of the environment, and in the way people perceive environmental issues. Christoph RoHner is interested in the movement and feeding ecology of large pelagic animals, and linking their behaviour to biological and oceanographic drivers. Ky m Collins specializes in the behaviour and acoustics of marine mammals. MARCELA RoseroCAICEDO is interested in marine conservation and specializes in scientific and environmental communication in volunteer programmes and local communities. Jod I SALmond studies Australian reef ecosystems in a global context, specializing in citizen science and marine education. Ara Monadjem is interested in the application of quantitative ecological techniques to conservation-related problems in small mammals and birds. Andrea Marshall studies the biology, ecology, monitoring and management of manta rays globally. Sim ON PIERCE is a marine conservation ecologist specializing in whale sharks. 